Article

\title{
Experimental Study of Artificial Ground Freezing by Natural Cold Gas Injection
}

\author{
Zhao Liu ${ }^{1,2,3}$, Youhong Sun $1,2,3,4, *$, Bingge Wang ${ }^{5}$ and Qiang $\mathrm{Li}^{1,2,3, *}$ \\ 1 Construction Engineering College, Jilin University, Changchun 130000, China; zhaoliu18@mails.jlu.edu.cn \\ 2 National-Local Joint Engineering Laboratory of In-situ Conversion, Drilling and Exploitation Technology for \\ Oil Shale, Changchun 130021, China \\ 3 Key Laboratory of Drilling and Exploitation Technology in Complex Condition, Ministry of Land and \\ Resource, Changchun 130026, China \\ 4 School of Engineering and Technology, China University of Geosciences, Beijing 100083, China \\ 5 Changchun Municipal Engineering Design \& Research Institute, Changchun 130000, China; \\ wangbg9527@163.com \\ * Correspondence: syh@jlu.edu.cn (Y.S.); qiangljlu@163.com (Q.L.)
}

Received: 16 July 2020; Accepted: 18 August 2020; Published: 1 September 2020

check for updates

\begin{abstract}
The application of conventional artificial ground freezing (AGF) has two disadvantages: low freezing rate and small frozen range. In this study, a new method with natural cold gas injection was proposed, whereby the shallow soils and water can be frozen rapidly due to the effect of the heat convection. Cold gas from $-15{ }^{\circ} \mathrm{C}$ to $-10{ }^{\circ} \mathrm{C}$, in the winter of northeast China, was injected into the laboratory-scale sand pipe; evolution of the induced frozen front and water migration were studied, and then, the feasibility of the new method was analyzed. According to the evolution of the induced frozen front, the freezing process was divided into an initial cooling stage, phase transition stage, and subcooled stage. The results showed that the increase of initial water content at the beginning of the experiments had little effect on the time required for completing the initial cooling stage, while the time required for the phase transition would increase in nearly the same proportion. In addition, the increase of the cold gas flow rate could not only strengthen the cooling rate of the initial cooling stage but also shorten the phase transition time; thereby, the freezing rate was increased. The freezing rate could reach $0.18-0.61 \mathrm{~cm} / \mathrm{min}$ in the direction of cold gas flow, and compared to the conventional AGF (months are required for approximately $1 \mathrm{~m}$ ), the freezing efficiency was greatly improved.
\end{abstract}

Keywords: artificial ground freezing; cold gas injection; heat convection; freezing rate; water migration

\section{Introduction}

Artificial ground freezing (AGF) is used to temporarily freeze the formation matrix and water together, which can improve the strength of soil and redirect the flow paths of groundwater. This method is widely used for deep excavation, tunnels construction, and strengthening building foundations, especially in soft rocks and shallow soils [1,2]. In general, AGF is realized by circulating refrigerant (generally low-temperature brine or liquid nitrogen) in a closed-loop system, where a double-walled pipe is used $[3,4]$.

In 1880, German engineer F.H. Poetch first proposed the artificial freezing method [5]. Recently, this method was generally accepted and applied. The construction of Nanjing Metro Line 2 in China used AGF to treat the inrush of water during excavation, in which brine at $-20{ }^{\circ} \mathrm{C}$, circulating in double-walled vertical pipes with well spacing of $1 \mathrm{~m}$, was used to freeze formations, and construction conditions were realized successfully after 40 days [6]. The Fürth subway and undercrossing of the Limmat River in Zurich were constructed using brine at $-40{ }^{\circ} \mathrm{C}$, circulating in horizontal pipes. 
The comprehensive frozen wall could be formed after 40 days, and the frozen radius of a single well was approximately $1 \mathrm{~m}$ [2]. In addition, for the first time, the combination of AGF and pipe-roofing was applied in the Gongbei tunnel that connects the Hong Kong-Zhuhai-Macao Bridge in order to obtain a safer construction environment [7].

In order to profoundly promote the development of AGF, scholars have conducted in-depth research by means of experiments and numerical analysis. Research on AGF mainly focused on the evolution of the induced frozen front and the frozen range. Many workers have studied freezing characteristics under different conditions, which have enriched the database available for application [8-11]. According to their results, the frozen radius of a single well was usually $0.5-1 \mathrm{~m}$, but several months were required, which meant that the freezing rate was low, with a limited frozen range. Innovatively, Zhao et al. used the natural cold source in the cold region to cool the cycle medium [12], which effectively reduced the cost of the freezing process, but the frozen range and freezing rate were not improved. Marwan et al. studied the law of artificial ground freezing with groundwater flow, and water flow would undoubtedly weaken the freezing effect and reduce the frozen range on the windward side, but the optimal layout of the freezing pipes was obtained through a numerical analysis $[13,14]$. Some mathematical models that consider hydro-thermal coupling characteristics have also been proposed to simulate the underground temperature field [15-18]. In addition, the frozen top layer of soil by cold air had been tried for mine pit construction during the wintertime in Siberia; then, the next layer of soil was frozen and excavated [19]. In addition, the effect of the water-ice phase transition on water migration in pores has been a research hotspot domestically and abroad [20-22], and the results show that moisture will move from the hot end to the cold end under a temperature gradient [23]. Meanwhile, the gravity and attraction of porous media should be taken into consideration.

In several studies, the way of circulating refrigerant in double-walled pipes was used to freeze formation by heat conduction, as shown in Figure 1a. It is well known that heat conduction is a slow and inefficient heat transfer mode compared to heat convection; so, this will result in a longer freezing time (months are required) and a limited frozen radius (approximately $1 \mathrm{~m}$ ). Meanwhile, the use of a large amount of refrigerant and a long freezing period has also increased construction costs, which deviates from the energy-efficient track promoted by the international community.
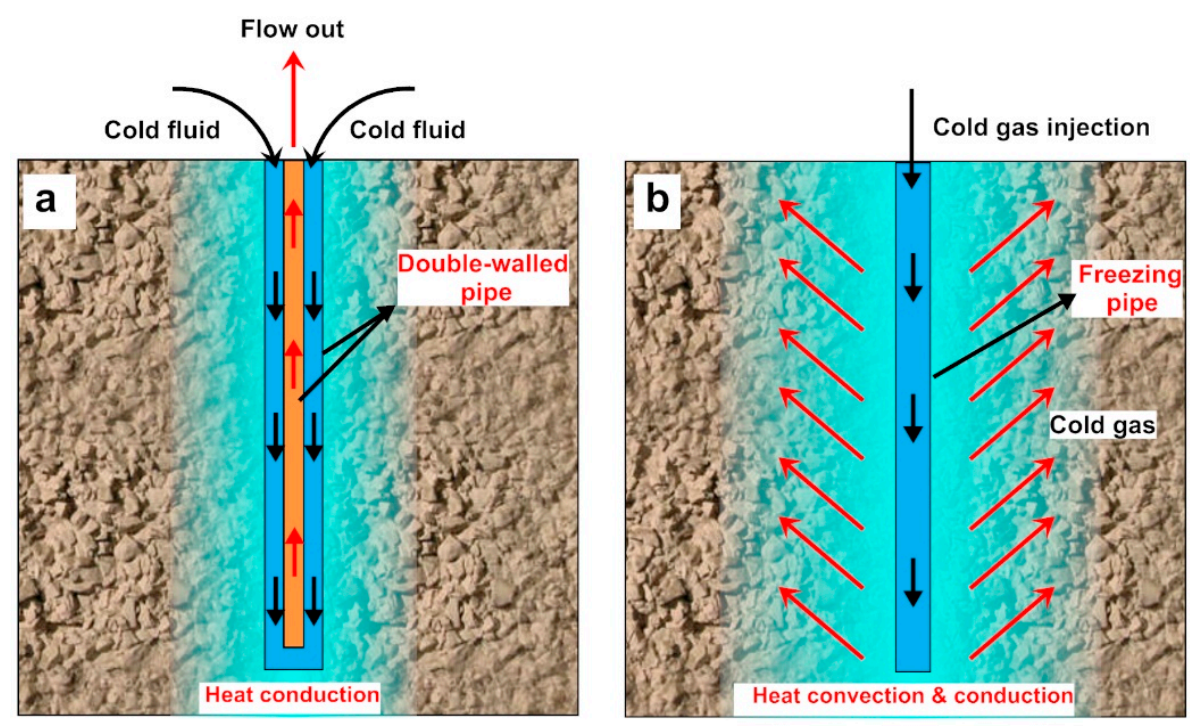

Figure 1. Schematic diagram of conventional artificial ground freezing (AGF) (a) compared to the proposed method (b), the blue area represents the frozen range.

Accordingly, in this study, as shown in Figure 1b, we consider directly injecting natural cold gas into the subsurface and then strengthening the freezing rate by heat convection. Cold gas injection 
into the ground is the primary technical process; in order to achieve this, a series of processes will be required. Firstly, a group of wells with a certain distance shall be arranged in the construction area. Secondly, it is necessary to adopt a gas compressor, heat exchanger, and other equipment to provide cold gas. According to previous research [12], natural heat exchange can reach the required low temperature in winter. After cold gas enters the formation under pressure, gas will not only flow laterally forward, but it will also move upward due to buoyancy. Finally, the surrounding soil is frozen by gold gas flow.

Natural cold gas in cold regions is a kind of abundantly available cold source; if fully utilized, the energy consumption during artificial ground freezing could be greatly reduced. In this study, the cold gas, from $-15{ }^{\circ} \mathrm{C}$ to $-10{ }^{\circ} \mathrm{C}$, in the winter of northeast China was injected into the water-bearing sand pipe. The solid-fluid thermal coupling characteristics and water migration were studied. Then, the effects of initial water content by weight and cold gas flow rate were also investigated. Meanwhile, the evolution of the induced frozen front was obtained during natural cold gas injection. As we know, the formation of ice will block pores, so the difficulty of cold gas injection (injectability) is also important. Therefore, the feasibility of the new method was discussed in terms of cold gas injectability and freezing efficiency.

\section{Experiment and Method}

\subsection{Experiment Setup}

In order to investigate the new method proposed in this study, laboratory experiments were conducted. As we all know, due to the buoyancy, gas tends to flow upward underground as shown in Figure $1 b$, so a vertical one-dimensional cylindrical freezing model was adopted. The freezing model is made of a stainless-steel pipe with an inner diameter of $80 \mathrm{~mm}$, an outer diameter of $89 \mathrm{~mm}$, and a length of $1 \mathrm{~m}$. A sufficient vertical dimension could ensure sufficient heat exchange and be conducive to the development of a larger frozen range. As shown in Figure 2, the bottom of the model acts as the inlet of cold gas with a surge chamber to homogenize cold gas flow, and the top acts as the outlet; two thermocouple temperature sensors (T1 and T6) were set accordingly. The freezing model was equipped with thermocouple temperature sensors (T2-T5) every $20 \mathrm{~cm}$ between two ends along the vertical direction ( $\mathrm{z}$ coordinate), the thermocouple temperature sensors used ranged from -50 to $50{ }^{\circ} \mathrm{C}$, with a calibration accuracy of $0.5 \%$; meanwhile, another thermocouple temperature sensor (T7) was set beside the nitrogen cylinder, outdoors, to monitor the ambient temperature in real time. The pressure sensors with an accuracy of $2.5 \%$ were arranged at the inlet and outlet to monitor pressure difference. Therefore, seven thermocouple temperature sensors and two pressure sensors were organized in total. A glass rotameter (LZB-10WB) was used to measure the gas flow rate with an accuracy of $2.5 \%$, which was installed at the entrance of the experimental model. The gas flow rate can also be adjusted through the glass rotameter $[24,25]$. The outer side of the stainless-steel pipe was wrapped with a heating cable; the initial temperature of the freezing model could be effectively controlled jointly by the heating cable and cold gas. The freezing model and injection pipes were tightly wrapped with insulating cotton; the thermal conductivity of the insulating cotton was $0.032 \mathrm{~W} /(\mathrm{m} \cdot \mathrm{K})$ so as to minimize the heat exchange between the freezing model and the external environment during the experiments. A KNOWELL paperless recorder was used for data acquisition in the experiments, and it can be accurate to two decimal places. Since a group of experiments took a long time, the temperature and pressure data fluctuated a little during the experiment; we set the data acquisition interval of temperature and pressure at $15 \mathrm{~s}$. 


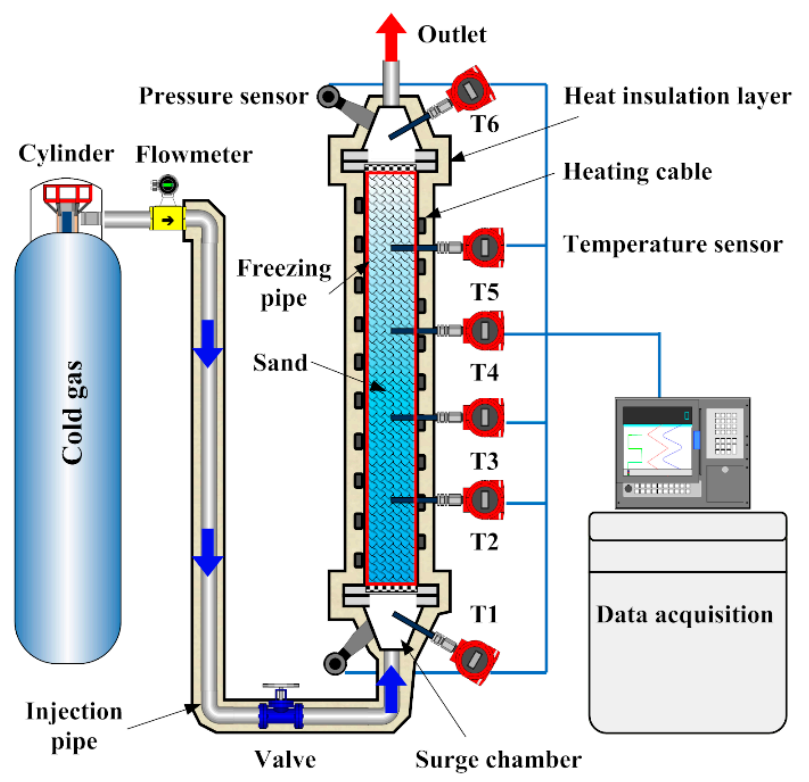

Figure 2. Principle diagram of freezing model and experimental device.

\subsection{Freezing Experiment}

This study mainly investigated the proposed new method; therefore, the main variables were the flow rate of cold gas and initial water content in the sand; other factors involved in the freezing process were not taken into account, such as frost heave and groundwater flow. The sand selected for the experiments is not sensitive to frost heave and has high strength; the specific parameters are shown in Table 1. The freezing pipe was filled with water-bearing sand and compacted. According to the initial water contents $(0.2$ and 0.4$)$, water was mixed with sands and then loaded into the model and compacted. The experimental site is located in Fuyu City, Jilin Province, China, one of the cold regions in China, where winter can last $4-5$ months, and the outdoor temperature is from -25 to $-10{ }^{\circ} \mathrm{C}$ for most of the winter. Such an abundant natural cold source is convenient for artificial freezing construction. Considering that the underground temperature is generally about $3-10{ }^{\circ} \mathrm{C}$, the initial temperature of the freezing pipe was controlled at approximately $5^{\circ} \mathrm{C}$, and then, the heat cable was stopped. In the experiments, cold gas was continuously supplied by a nitrogen cylinder with a pre-pressurized pressure of $10 \mathrm{MPa}$, which was placed outdoors in order to ensure that the gas temperature was equivalent to the outdoor temperature, and then the experiments started.

Table 1. Physical properties of sand.

\begin{tabular}{cccccc}
\hline $\begin{array}{c}\text { Sand } \\
\text { Type }\end{array}$ & Mesh Size & Packed Porosity & $\begin{array}{c}\text { Density } \\
\left(\mathbf{K g} / \mathbf{m}^{\mathbf{3}}\right)\end{array}$ & $\begin{array}{c}\text { Thermal } \\
\text { Conductivity } \\
(\mathbf{W} /(\mathbf{m} \cdot \mathbf{K}))\end{array}$ & $\begin{array}{c}\text { Specific Heat } \\
\text { Capacity } \\
\left.\left(\mathbf{K J} / \mathbf{K g} \cdot{ }^{\circ} \mathbf{C}\right)\right)\end{array}$ \\
\hline Ceramsite sand & $40-70$ & 0.39 & 1100 & 1.15 & 0.961 \\
\hline
\end{tabular}

After each experiment, the sand samples were collected at the point of the inlet, T2, T3, T4, and T5, and the outlet to calculate the total water content by weight; the specific calculation method was as follows. The wet and dry weights of the samples prior to experiments are $M_{o w}$ and $M_{o d}$, respectively, and the initial water content of the freezing model is $\theta_{0}$. After the experiments, the same values are weighed as $M_{w}$ and $M_{d}$. The water content $\theta$ of the samples after the experiment can be calculated by the following formula:

$$
\theta=\theta_{0} \times \frac{\left(M_{w}-M_{d}\right) \times M_{o d}}{\left(M_{o w}-M_{o d}\right) \times M_{d}}
$$


In order to preliminarily study the evolution of temperature in the freezing model during natural cold gas injection and to verify the feasibility of the new method, four groups of experiments were carried out. The initial water content was 0.2 and 0.4 ; in addition, we optimized and used the two gas flow rates, $15 \mathrm{~L} / \mathrm{min}$ and $25 \mathrm{~L} / \mathrm{min}$. We also tested the gas flow rate intermittently by the dewatering method in each experiment [18], and it was verified that the flow fluctuation was not more than $0.2 \mathrm{~L} / \mathrm{min}$. The specific experimental conditions were as shown in Table 2.

Table 2. Experimental design ${ }^{\mathrm{a}}$.

\begin{tabular}{ccc}
\hline $\begin{array}{c}\text { Experiment } \\
\text { Number }\end{array}$ & $\begin{array}{c}\text { Initial Water } \\
\text { Content }\end{array}$ & $\begin{array}{c}\text { Gas Flow Rate } \\
\text { (L/min) }\end{array}$ \\
\hline 1 & 0.2 & $15 \pm 0.2$ \\
2 & 0.2 & $25 \pm 0.2$ \\
3 & 0.4 & $15 \pm 0.2$ \\
4 & 0.4 & $25 \pm 0.2$ \\
\hline
\end{tabular}

a The initial temperature of the freezing pipe is $5^{\circ} \mathrm{C}$.

\section{Results}

\subsection{Thermal Characteristic}

The evolution of temperature in the freezing model is the main thermal characteristic during natural cold gas injection, which reflects the development of the frozen range. Figure 3 depicts the change of temperature at each monitoring point. Obviously, the natural cold gas used in the experiments was in the range of -15 to $-10^{\circ} \mathrm{C}$, and the temperature of each point experienced a slow decrease, and then a sharp drop in temperature occurred at approximately $0{ }^{\circ} \mathrm{C}$. Before the temperature in the freezing model dropped below $0{ }^{\circ} \mathrm{C}$, the water had not been frozen yet, and the thermal conductivity of the water, $0.613 \mathrm{~W} /(\mathrm{m} \cdot \mathrm{K})$, is much lower than that of ice, which is $2.31 \mathrm{~W} /(\mathrm{m} \cdot \mathrm{K})$. Therefore, the temperature reduction rate at each point was slower, and the farther away it was from the inlet, the slower it would be. This stage can be regarded as the initial cooling stage. When the temperature decreased to about $0{ }^{\circ} \mathrm{C}$, the sand pores were in the state of water-ice two-phase coexistence. The phase transition of water into ice released a lot of latent heat [26], which was absorbed by cold gas, and the temperature was almost unchanged; this is the phase transition stage. As the temperature continued to decrease, water in the pores gradually turned into ice and latent heat was released completely. The surface of sand changed from water-encapsulated to ice-encapsulated, accordingly, and the thermal conductivity was greatly increased. Therefore, it can be seen from Figure 3 that the temperature dropped sharply below $0{ }^{\circ} \mathrm{C}$, and rapidly to the same level as the cold gas. This area can be regarded as completely frozen, and this stage is the subcooled stage. It is noteworthy that the throttling effect may occur at the outlet of the cylinder due to the sudden drop of pressure, which made the gas temperature lower than the measured ambient temperature. Therefore, it can be seen from Figure $3 \mathrm{~b}, \mathrm{~d}$ that the temperature (T1) at some points would be lower than the ambient temperature (T7), which was not obvious in the low gas flow rate.

In order to compare the differences between the three stages more intuitively under different flow rates and initial water contents, we took the temperature at the T2 position $(20 \mathrm{~cm}$ away from the inlet) as an example to analyze the freezing characteristics. Figure 4 depicts the comparison of temperatures at the $\mathrm{T} 2$ position in each experiment. In the initial cooling stage, it can be seen from Figure $4 \mathrm{c}, \mathrm{d}$ that the initial water content changed from 0.2 to 0.4 , and there was little difference in the time needed to reduce the temperature to $0{ }^{\circ} \mathrm{C}$. It means that the cooling rate was the same under different water contents. However, that could be greatly improved by increasing the flow rate of the cold gas (Figure 4a,b), because the increase in water content in the pores did not increase the internal energy per unit volume significantly, while the increase in the flow rate could directly enhance the convective heat transfer intensity; thus, the flow rate of cold gas played a leading role in the initial 
cooling rate. In the phase transition stage, it can be seen from Figure $4 c, d$ that the time required for the phase transition increased by, essentially, the same proportion as the initial water content as it doubled, while it could also be reduced by increasing the flow rate of the cold gas. The evolution characteristics of temperature in the initial cooling stage and phase transition stage directly affected the freezing rate. From the above, increasing the initial water content would delay it completely freezing, and increasing the flow rate of cold gas could quickly make the soil completely frozen.
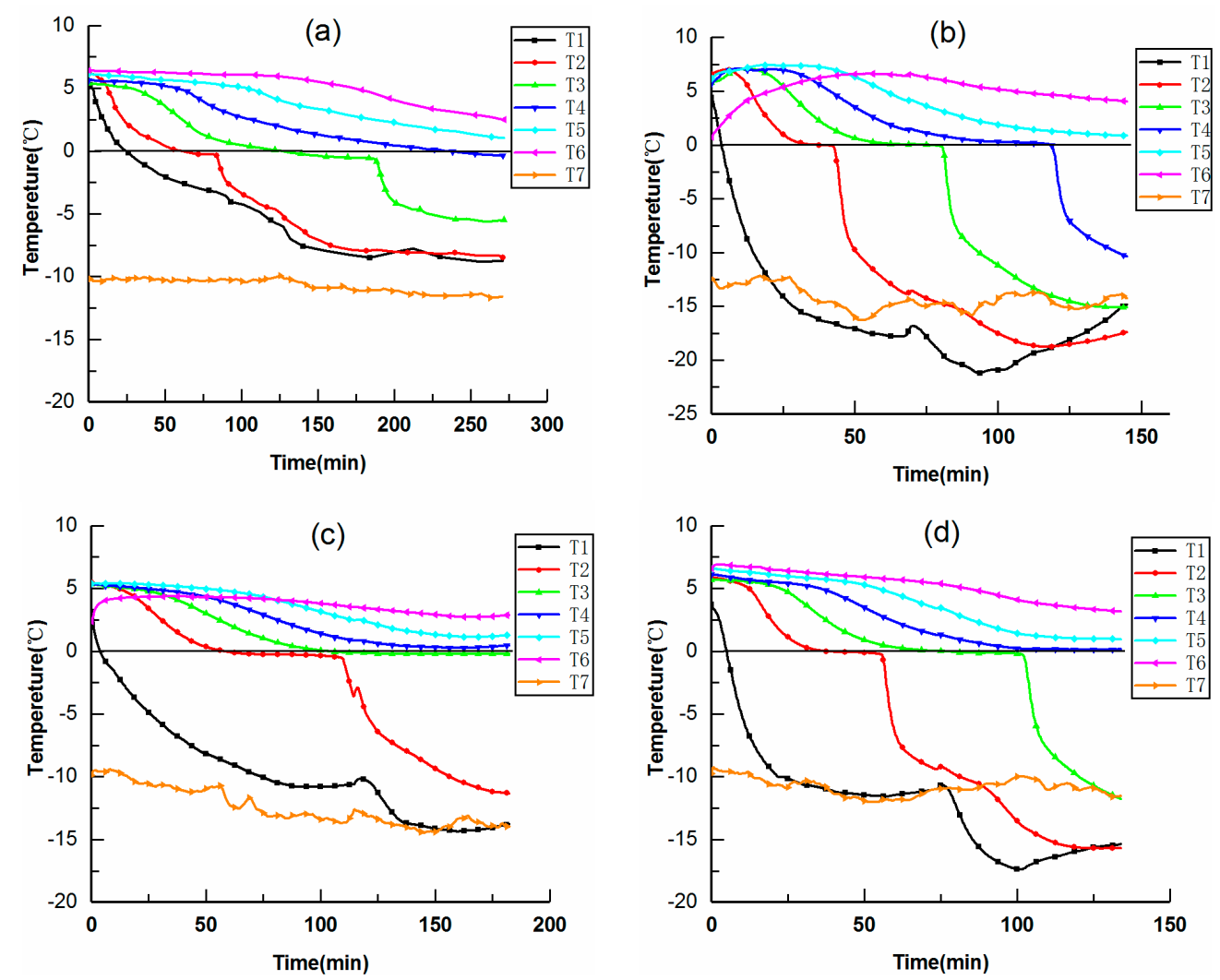

Figure 3. Evolution of the temperature in the freezing model during natural cold gas injection ((a) Experiment 1, (b) Experiment 2, (c) Experiment 3, (d) Experiment 4; and T7 represents ambient temperature).

The freezing rate can be regarded as an important index to evaluate the new method. According to the evolution of the temperature in Figure 3, the freezing rates in the experiments were summarized, as shown in Table 3. During the calculation of the freezing rate, the end point of the phase transition in Figure 3 at each monitoring point acted as completely frozen. Therefore, the freezing rate can be regarded as the ratio of each segment length to the time required for completely frozen from its front to end. In addition, because of the high initial water content, experiments 3 and 4 did not proceed to being completely frozen in the T3-T4 section. As the method proposed in this study converts the heat conduction into heat convection, it was shown that that the freezing rates were almost all in the range of $0.18-0.6 \mathrm{~cm} / \mathrm{min}$, which was a significant improvement, in comparison to the conventional AGF (months are required for approximately $1 \mathrm{~m}$ ) [5-7,18]. Therefore, the measure of direct injection of natural cold gas could obtain a better strengthening effect. It is noteworthy that under the same initial water content conditions, the increase of the cold gas flow rate could increase the freezing rate of each section, while increasing the water content would increase the water-ice phase transition time and then reduce the freezing rate. The reason why there were no significant differences in the freezing rates between experiments 2 and 4 may be that the ambient temperature of experiment 2 was lower than that of experiment 4 . In addition, fluctuation of the cold gas temperature will have some influence 
on the results; as shown in Figure 3c, the temperature during experiment 3 continuously decreases, which may result in a higher freezing rate.
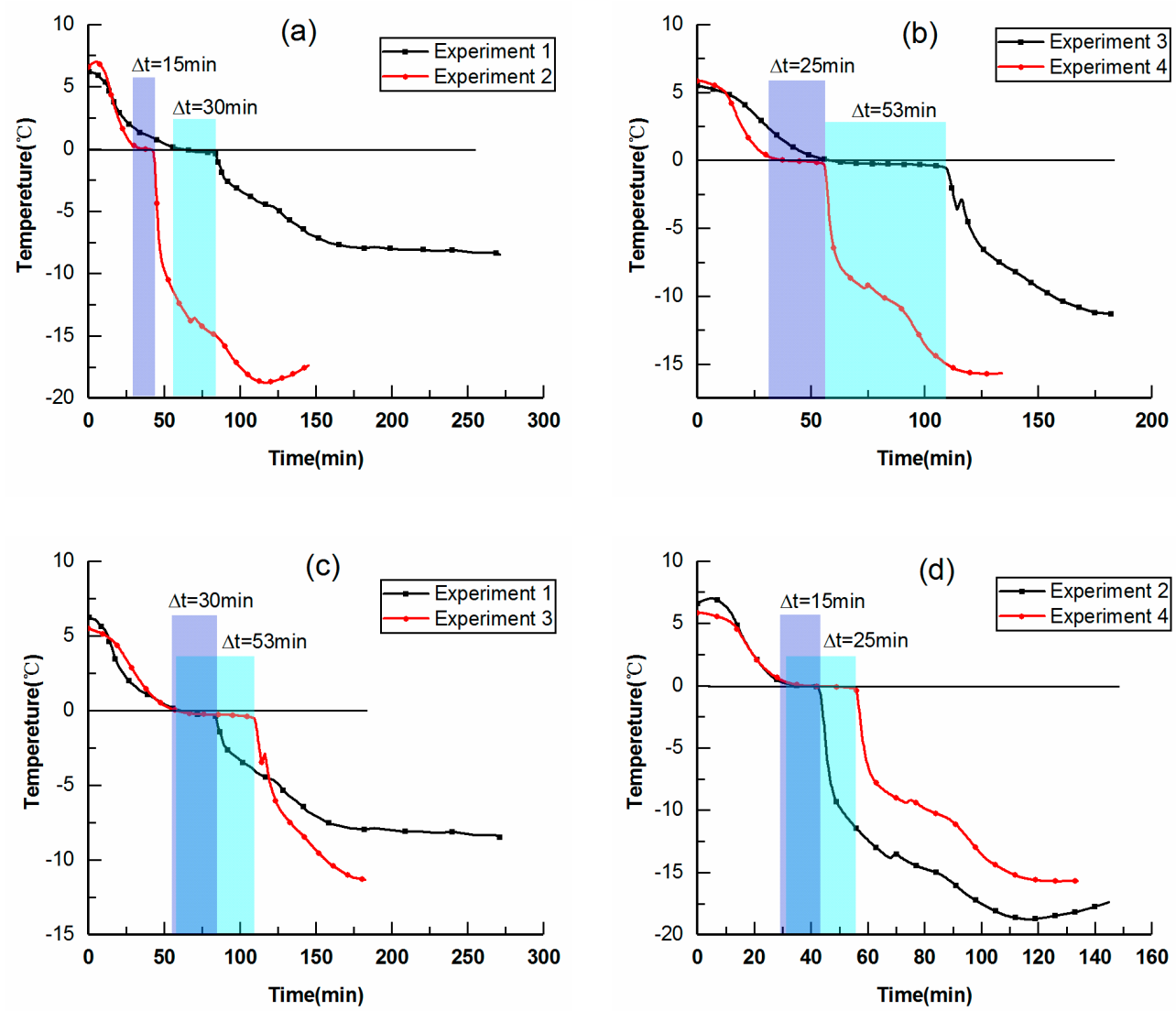

Figure 4. Comparison of temperature change at the T2 position in different conditions; $(\mathbf{a}, \mathbf{b})$ depict the influence of gas flow rate, $(\mathbf{c}, \mathbf{d})$ depict the influence of initial water content.

Table 3. Freezing rate of each section.

\begin{tabular}{cccc}
\hline Experiment Number & $\begin{array}{c}\text { Freezing Rate of T1-T2 } \\
\text { (cm/min) }\end{array}$ & $\begin{array}{c}\text { Freezing Rate of T2-T3 } \\
\text { (cm/min) }\end{array}$ & $\begin{array}{c}\text { Freezing Rate of T3-T4 } \\
\text { (cm/min) }\end{array}$ \\
\hline 1 & 0.46 & 0.33 & 0.18 \\
2 & 0.60 & 0.52 & 0.47 \\
3 & 0.37 & 0.44 & - \\
4 & 0.61 & 0.52 & - \\
\hline
\end{tabular}

\subsection{Flow Field Characteristics}

Natural cold gas injection can not only cause the water-ice phase transition but also displace pore water. Therefore, in these experiments, a coupling physical field of two-phase flow and water-ice phase transition existed in the freezing model. The pressure difference between the inlet and outlet of the freezing model could indirectly reflect the change of the gas-water two-phase flow field and reflect the redistribution of water.

Figure 5 depicts the pressure differences between the inlet and outlet of the freezing model in the experiments. As the flow valve needed to be adjusted irregularly in order to maintain the stability of the flow rate, the flow rate would fluctuate, which was also the reason for the fluctuation of the pressure differences measured in real time. According to the fitting curves of the pressure differences shown in Figure 5, it showed that in the early stages of cold gas injection, the reduction rates of pressure differences was relatively large, and after about 50 minutes, the reduction rates slowed down. In the process of gas injection, water in the pores would redistribute under the displacement of gas flow, 
where numerous smooth and stable gas flow channels gradually formed. Before the formation of the gas channels, part of the pores was filled with water and the path of the gas flow was blocked, resulting in a large pressure difference in the early stage. After a certain period of gas flooding, some pore throats were opened, and water redistributed. Numerous gas channels (Figure $6 a, b$ ) were formed in the pores between sand grains, which reduced the gas flow resistance. Therefore, the reduction of pressure differences slowed down later.
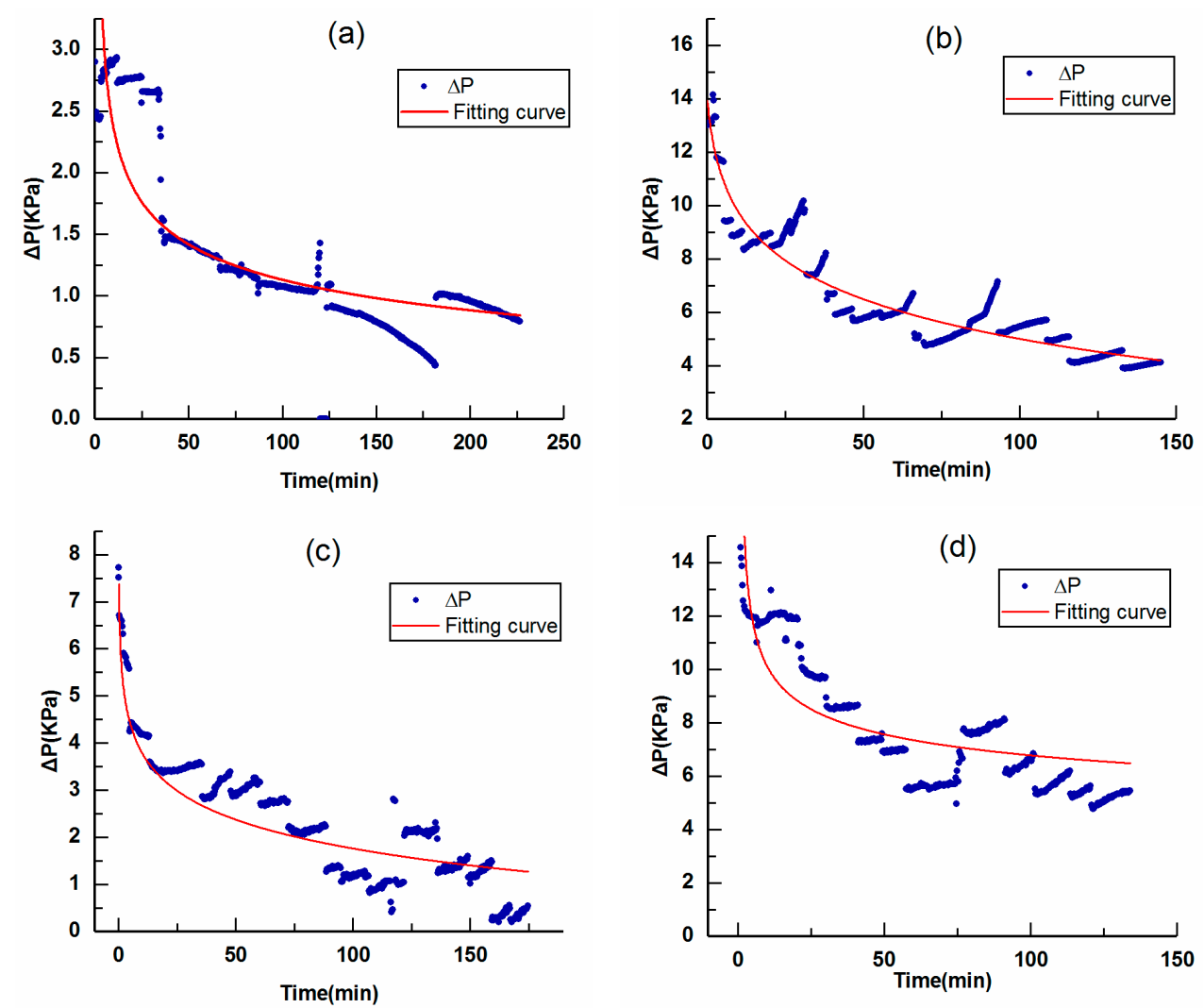

Figure 5. Pressure difference between two ends of the freezing model during natural cold gas injection ((a) Experiment 1, (b) Experiment 2, (c) Experiment 3, and (d) Experiment 4).
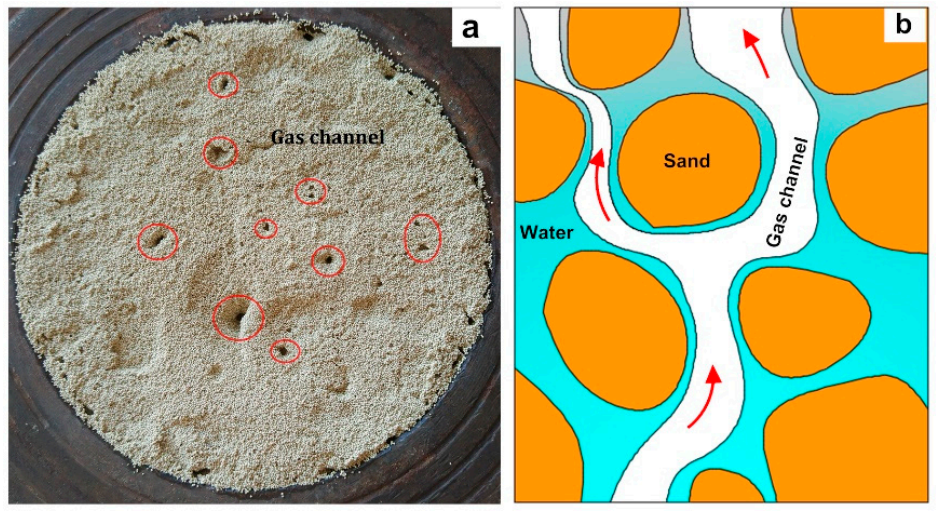

Figure 6. Gas channels. (a) Gas channels in the outlet after injection, (b) Diagram of gas channels in pores.

However, the water-ice phase transition also occurred in the pores, because of the expansion of the water volume during freezing, and the pore spacing between sand grains was enlarged, which would undoubtedly reduce the flow resistance of gas. The coupling of the water-ice phase transition and displacement reduced the pressure differences gradually. This reduction phenomenon of pressure 
difference can decrease the difficulty of natural cold gas injection, which is beneficial to the actual artificial freezing construction.

AGF can not only improve the strength of soil, but also block groundwater flow. Freezing of the water-bearing sand will undoubtedly increase the strength of soil; however, when groundwater outside the frozen area flows in, water will change into ice under the effect of the subcooled environment, and then the flow passage will be blocked [27]. Meanwhile, after displacement by the gas flow, the gas phase saturation in the pores would increase, and the block effect on groundwater flow will be improved with the aid of the gas resistance [28,29].

\subsection{Water Migration during Cold Gas Injection}

As mentioned above, water redistribution under the coupling effect of displacement and phase transition will affect the temperature field. Water in the vertical freezing model was not only adsorbed by sand but also affected by gravity; meanwhile, the upward force was exerted by the gas flow. Therefore, the combination of these three forces determines the direction of water migration. Figure $7 \mathrm{a}, \mathrm{b}$ depicts the redistribution of water after experiments with initial water content of 0.2 and 0.4 , respectively. From Figure 7a, it can be seen that except for the significant reduction at the inlet, the other parts decreased slightly-roughly in the range of 0.16-0.2. Obviously, the gas humidity was small at the entrance; a part of the water in the pores would be carried away by the gas flow (drying effect), which reduced the water content. Due to the low initial water content, most of the water was encapsulated on the sand surface and adsorbed, even under the displacement of gas flow and gravity, and it was difficult to migrate to a greater extent: it only evaporated under the drying effect of the gas flow. Increasing the flow rate of cold gas would also increase the volatilization of water. Therefore, when the flow rate was $25 \mathrm{~L} / \mathrm{min}$, the overall moisture content was relatively low after the experiment. From Figure $7 \mathrm{~b}$, it showed that water migration at high initial water contents presented the opposite law. The moisture content near the inlet was greatly increased, reaching between 0.6 and 0.75 , and the further it was from the inlet, the lower the saturation of water. As only a part of the water was adsorbed on the surface of the sand particles, which was difficult to move, the rest could migrate under the action of gravity and gas flooding. According to the foregoing analysis, after stable gas flow channels formed, the gas flow rate outside the channels was low, which made the water migrate downward under the dominated action of gravity. It was noteworthy that when the initial water content was 0.4 , increasing the flow rate would increase the upward force of water migration, thus making the water content at the lower end of the freezing model less than $15 \mathrm{~L} / \mathrm{min}$, while the upper end of the model was the opposite. However, freezing of the water started from the bottom; the frozen water in the pores also attracted water in the upper part to move toward the frozen front. Therefore, the attraction of the frozen front to water would also redistribute water in the pores.
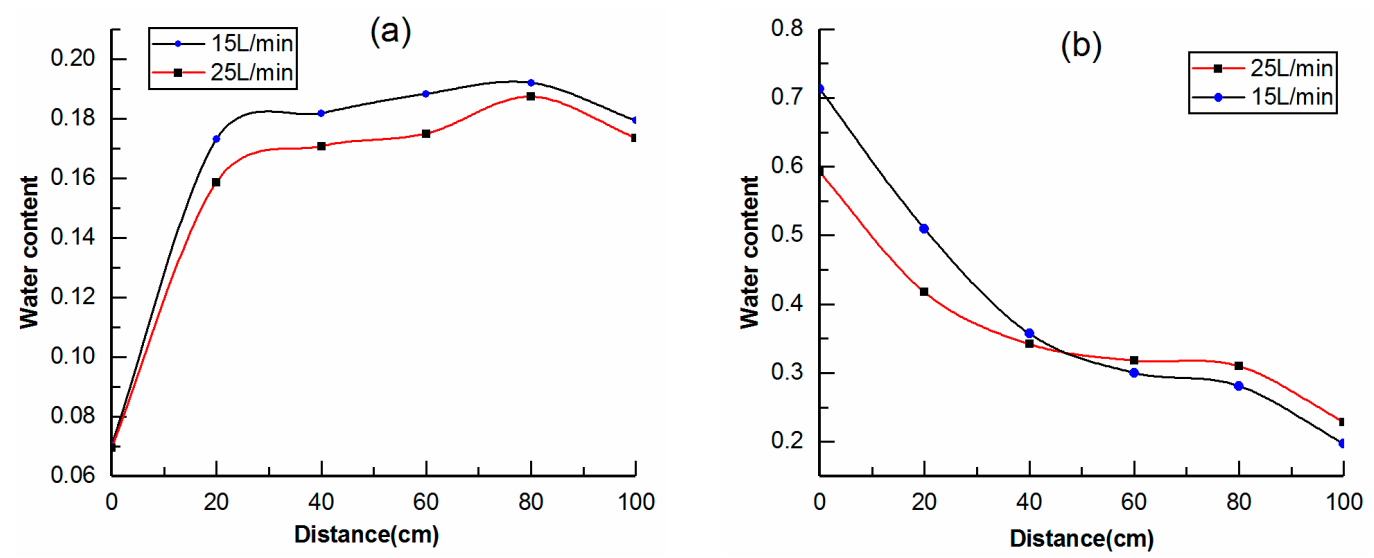

Figure 7. Water distribution after cold gas injection (a) Initial water content was 0.2 , (b) Initial water content was 0.4 . 


\section{Discussion}

\subsection{Solid-Fluid Thermal Coupling Characteristics}

As opposed to conventional AGF, natural cold gas was injected directly to freeze the formation in a heat convection manner. Therefore, during the freezing process of sand and water, there was not only a water-ice phase transition, but also the redistribution of water driven by gas flooding, the attraction of the frozen front, and gravity, and the two characteristics interacted with each other. Heat in the freezing model was carried away by the cold gas flow, which led to the gradual freezing. The state of water in the pores was changed from a liquid to an ice-water mixtur, and then to solid ice; meanwhile, the expansion effect caused by freezing will change the pore characteristics. The enlargement of sand spacing caused by phase transition would affect the redistribution of water; then, the gas-water two-phase flow affected it. Cold gas injection enhances the freezing rate by the heat convection transfer; therefore, the change of the two-phase flow field is bound to affect the evolution of the induced frozen front. As mentioned before, there are many external causes that will lead to the redistribution of water, which is the main factor for the change in the formation of the thermodynamic properties. Therefore, the process of cold gas injection involved the coupling effects of water migration and heat transfer. Consequently, the solid-fluid thermal coupling characteristics determined the freezing effect of cold gas injection proposed in this paper.

\subsection{Analysis of Feasibility}

There are two main factors affecting the feasibility of the method proposed in this studythe freezing rate and the injectability of cold gas. According to the above results, there is no doubt that cold gas injection can ensure a high freezing rate. At the same time, the decrease in the pressure drop is also conducive to the injection of cold gas; therefore, the injectability of cold gas can also be guaranteed.

In this study, the influences of soil type and gas injection direction were ignored, but the influences of these two factors can be roughly inferred based on the above results. First of all, the frost-heaving characteristics and particle size distribution of soil primarily affect the flow of fluids, and then they affect the injectability of cold gas. The injectability mainly depends on the opening of gas flow channels; based on the above results, gas flooding can quickly open the gas flow channels before the pore water is frozen. Therefore, we can infer that for homogeneous soils, the existence of gas flooding can ensure the opening of gas flow channels, so as to guarantee the injectability of cold gas. For heterogeneous soil, the permeability difference is the main characteristic. In general, cold gas will flow along the direction of high permeability; this area will be frozen first. Then, cold gas flow turns to the low permeability matrix. In addition, existence of the firstly frozen area will freeze the surrounding low-permeability area by heat conduction. Therefore, cold gas flow has the potential to freeze heterogeneous media successively. However, there are several application limitations of this new method on the fractured formation; for example, cold gas may flow away from the fractures. In addition, the injection direction of gas was set as upward in this study, under the action of buoyancy, the flow of gas will undoubtedly speed up, and then, the cooling rates were improved. However, compared to the driving force of gas injection, the effect of buoyancy appears very small. It should be noted that the cold gas will gather to the upper part of the formation due to buoyancy in the actual construction process, but in the near source area, gas will tend to flow laterally under the driving force of injection. Therefore, the "cylindrical" frozen range around the injection well can be achieved. In conclusion, the method proposed in this study has a high freezing rate with strong applicability. However, considering the low heat capacity of gas, the further away from the gas injection point, the lower the freezing rate. Therefore, in the actual construction process, the frozen range of a single well should be designed reasonably. Perhaps a range of approximately $3 \mathrm{~m}$ is appropriate.

In addition, the impacts of gas injection and displacement of water on structural instabilities need to be considered. Gas injection, performing various roles in porous media, is involved in several domains; in this work, we adopt cold gas injection to freeze the soil. Without a doubt, local variations 
of underground pressure and structural disturbance will be brought about by cold gas injection, but according to the previous research of gas injection (e.g., air sparging, new Austrian Method of tunnel construction), no obvious negative effect will be caused [30-32]. In addition, the flow rate can also be controlled to reduce the impact on the formation. Therefore, the impact of gas injection and displacement of water can be controlled to ensure safe construction.

\section{Conclusions}

In this study, a new method of artificial ground freezing by natural cold gas injection was proposed. The measure was studied and verified through laboratory experiments, and the solid-fluid thermal coupling characteristics during cold gas injection were obtained. According to the research results, the specific conclusions are as follows:

1. A new method of natural cold gas injection was proposed to construct an artificial ground freezing structure, which uses the manner of heat convection to enhance the freezing rate. According to the experiments, the freezing rates could reach $0.18-0.61 \mathrm{~cm} / \mathrm{min}$.

2. According to the characteristics of the temperature curves, the freezing process was divided into the initial cooling stage, phase transition stage, and subcooled stage. The duration of the initial cooling stage and phase transition stage will directly affect the freezing rate. Increasing the initial water content had less effect on the initial cooling stage, and the time required for the phase transition would increase in nearly the same proportion. Increasing the cold gas flow rate could not only increase the cooling rate in the initial cooling stage but also shorten the phase transition time, thereby increasing the freezing rate.

3. The law of water migration during cold gas injection was obtained. Driven by gas flooding, attraction of the frozen front, sand adsorption and gravity, and water in the pores would redistribute. When the water content was low, except for the significant reduction at the inlet, the other parts decreased slightly-roughly in the range of 0.16-0.2. When the water content was high, the moisture content near the inlet was greatly increased, reaching between 0.6 and 0.75 , and the further it was from the inlet, the lower the water content.

4. The feasibility of the method was analyzed. The method proposed in this study has a high freezing rate and can be well applied in homogeneous soils. However, considering the low heat capacity of gas, the frozen range of a single well should be designed reasonably in the actual construction process; a range of approximately $3 \mathrm{~m}$ may be appropriate.

Author Contributions: Conceptualization, Y.S. and Q.L.; Investigation, Z.L.; Methodology, Q.L. and B.W.; Writing-original draft, Z.L. All authors have read and agreed to the published version of the manuscript.

Funding: This research was funded by the Cooperative Project between Universities and Jilin Province, China, grant number: SF2017-5-1, the Program for JLU Science and Technology Innovative Research Team, grant number: 2017TD-13, and the National Key R\&D Program of China (grant No. 2019YFA0705502, grant No. 2019YFA0705501).

Acknowledgments: We are appreciative of the insightful comments to our manuscript from anonymous reviewers, which are beneficial for improving our work.

Conflicts of Interest: The authors declare no conflict of interest.

\section{References}

1. Russo, G.; Corbo, A.; Cavuoto, F.; Autuori, S. Artificial Ground Freezing to excavate a tunnel in sandy soil. Measurements and back analysis. Tunn. Undergr. Space Technol. 2015, 50, 226-238. [CrossRef]

2. Pimentel, E.; Papakonstantinou, S.; Anagnostou, G. Numerical interpretation of temperature distributions from three ground freezing applications in urban tunnelling. Tunn. Undergr. Space Technol. Inc. Trenchless Technol. Res. 2012, 28, 57-69. [CrossRef]

3. Andersland, O.B.; Ladanyi, B. Frozen Ground Engineering; American Society of Civil Engineers: Hunter Mill, VA, USA, 2004. 
4. Mauro, A.; Normino, G.; Cavuoto, F.; Marotta, P.; Massarotti, N. Modeling Artificial Ground Freezing for Construction of Two Tunnels of a Metro Station in Napoli (Italy). Energies 2020, 13, 1272. [CrossRef]

5. Ries, A. Historical and technical development of the freezing process in shaft sinking. Gluckauf 1982, 118, e8.

6. Hu, J.; Liu, Y.; Li, Y.; Yao, K. Artificial Ground Freezing In Tunnelling Through Aquifer Soil Layers: A Case Study in Nanjing Metro Line 2. KSCE J. Civ. Eng. 2018, 22, 4136-4142. [CrossRef]

7. Hu, X.; Fang, T.; Chen, J.; Ren, H.; Guo, W. A large-scale physical model test on frozen status in freeze-sealing pipe roof method for tunnel construction. Tunn. Undergr. Space Technol. 2018, 72, 55-63. [CrossRef]

8. Lackner, R.; Pichler, C.; Kloiber, A. Artificial Ground Freezing of Fully Saturated Soil: Viscoelastic Behavior. J. Eng. Mech. 2008, 134, 1-11. [CrossRef]

9. Zhou, J.; Tang, Y. Artificial ground freezing of fully saturated mucky clay: Thawing problem by centrifuge modeling. Cold Reg. Sci. Technol. 2015, 117, 1-11. [CrossRef]

10. Vitel, M.; Rouabhi, A.; Tijani, M.; Guérin, F. Modeling heat transfer between a freeze pipe and the surrounding ground during artificial ground freezing activities. Comput. Geotech. 2015, 63, 99-111. [CrossRef]

11. Song, W.; Zhang, Y.; Li, B.; Fan, X. A lattice Boltzmann model for heat and mass transfer phenomena with phase transformations in unsaturated soil during freezing process. Int. J. Heat Mass Transf. 2016, 94, $29-38$. [CrossRef]

12. Zhao, D.J.; Liu, Y.M.; Sun, Y.H.; Zhao, Y.; Bai, F.T. Experiments and simulations of underground artificial freezing with the use of natural cold resources in cold regions. Build. Environ. 2015, 87, 224-233. [CrossRef]

13. Marwan, A.; Zhou, M.M.; Zaki Abdelrehim, M.; Meschke, G. Optimization of artificial ground freezing in tunneling in the presence of seepage flow. Comput. Geotech. 2016, 75, 112-125. [CrossRef]

14. Huang, S.; Guo, Y.; Liu, Y.; Ke, L.; Liu, G.; Chen, C. Study on the influence of water flow on temperature around freeze pipes and its distribution optimization during artificial ground freezing. Appl. Therm. Eng. 2018, 135, 435-445. [CrossRef]

15. Mahmoud, A.; Alzoubi, A.M.; Hassani, F.P.; Sasmito, A.P. Heat transfer analysis in artificial ground freezing under high seepage: Validation and heatlines visualization. Int. J. Therm. Sci. 2019, 139, 232-245.

16. Alzoubi, M.A.; Aurelien, N.R.; Sasmito, A.P. Conjugate heat transfer in artificial ground freezing using enthalpy-porosity method: Experiments and model validation. Int. J. Heat Mass Transf. 2018, 126, 740-752. [CrossRef]

17. Mahmoud, A.; Alzoubi, A.P.; Sasmito, A.M.; Madiseh, A.; Hassani, F.P. Intermittent Freezing Concept for Energy Saving in Artificial Ground Freezing Systems. Energy Procedia 2017, 142, 3920-3925.

18. Hu, R.; Liu, Q.; Xing, Y. Case Study of Heat Transfer during Artificial Ground Freezing with Groundwater Flow. Water 2018, 10, 1322. [CrossRef]

19. Popov, Y.A.; Sadlei, B.V.; Dzyubenko, L.F. Hydraulic excavation in the wintertime in Siberia. Hydrotech. Constr. 1985, 19, 573-576. [CrossRef]

20. Iwata, S. Driving force for water migration in frozen clayey soil. Soil Sci. Plant Nutr. 1980, 26, $215-227$. [CrossRef]

21. Ming, F.; Li, D.Q. A model of migration potential for moisture migration during soil freezing. Cold Reg. Sci. Technol. 2016, 124, 87-94. [CrossRef]

22. Ma, W.; Zhang, L.; Yang, C. Discussion of the applicability of the generalized Clausius-Clapeyron equation and the frozen fringe process. Earth Sci. Rev. 2015, 142, 47-59. [CrossRef]

23. Hoekstra, P. Moisture movement in soils under temperature gradients with the cold-side temperature below freezing. Water Resour. Res. 2010, 2, 241-250. [CrossRef]

24. Song, X.; Zhao, Y.; Wang, H.; Qin, C. Predictive models and airflow distribution associated with the zone of influence (ZOI) during air sparging remediation. Sci. Total Environ. 2015, 537, 1-8. [CrossRef] [PubMed]

25. Veillon, C.; Park, J.Y. Correct procedures for calibration and use of rotameter-type gas flow measuring devices. Anal. Chem. 1970, 42, 684-685. [CrossRef]

26. Go, G.H.; Lee, J.; Shin, H.S.; Ryu, B.H.; Jin, H.W.; Kin, D.W. Evaluation of one-dimensional freezing behavior for ice-rich sandy soil. Int. J. Heat Mass Transf. 2019, 130, 960-967. [CrossRef]

27. Fourie, W.J.; Barnes, D.L.; Shur, Y. The formation of ice from the infiltration of water into a frozen coarse grained soil. Cold Reg. Sci. Technol. 2007, 48, 1-128. [CrossRef]

28. Dror, I.; Berkowitz, B.; Gorelick, S.M. Effects of air injection on flow through porous media: Observations and analyses of laboratory-scale processes. Water Resour. Res. 2004, 40, W09203. [CrossRef] 
29. Sun, Y.; Liu, Z.; Li, Q.; Guo, W. Controlling groundwater infiltration by gas flooding for oil shale in situ pyrolysis exploitation. J. Pet. Sci. Eng. 2019, 179, 444-454. [CrossRef]

30. Safety Executive. Safety of New Austrian Tunnelling Method (NATM) Tunnels: A Review of Sprayed Concrete Lined Tunnels with Particular Reference to London Clay; Transport Research Laboratory: Crowthorne, UK, 1996.

31. Yoshimura, H.; Yuki, T.; Yamada, Y.; Kokubun, N. Analysis and monitoring of the Miyana railway tunnel constructed using the New Austrian tunnelling method. Int. J. Rock Mech. Min. Geomech. Abstr. 1986, 23, 67-75. [CrossRef]

32. Johnson, P.C.; Johnson, R.L.; Neaville, C.; Hansen, E.E.; Stearns, S.M.; Dortch, I.J. An assessment of conventional in situ air sparging pilot tests. Ground Water 2010, 35, 765-774. [CrossRef]

(C) 2020 by the authors. Licensee MDPI, Basel, Switzerland. This article is an open access article distributed under the terms and conditions of the Creative Commons Attribution (CC BY) license (http://creativecommons.org/licenses/by/4.0/). 